\title{
Tropical Tropospheric Temperature Variations Caused by ENSO and Their Influence on the Remote Tropical Climate*
}

\author{
JOHN C. H. CHIANG \\ Joint Institute for the Study of the Atmosphere and Ocean, University of Washington, Seattle, Washington, and \\ Department of Geography, University of California, Berkeley, Berkeley, California \\ ADAM H. SOBEL \\ Department of Applied Physics and Applied Mathematics and Department of Earth and Environmental Sciences, \\ Columbia University, New York, New York
}

(Manuscript received 20 August 2001, in final form 12 February 2002)

\begin{abstract}
The warming of the entire tropical free troposphere in response to El Niño is well established, and suggests a tropical mechanism for the El Niño-Southern Oscillation (ENSO) teleconnection. The potential impact of this warming on remote tropical climates is examined through investigating the adjustment of a single-column model to imposed tropospheric temperature variations, assuming that ENSO controls interannual tropospheric temperature variations at all tropical locations. The column model predicts the impact of these variations in three typical tropical climate states (precipitation $>$ evaporation; precipitation < evaporation; no convection) over a slab mixed layer ocean. Model precipitation and sea surface temperature (SST) respond significantly to the imposed tropospheric forcing in the first two climate states. Their amplitude and phase are sensitive to the imposed mixed layer depth, with the nature of the response depending on how fast the ocean adjusts to imposed tropospheric temperature forcing. For larger mixed layer depth, the SST lags the tropospheric temperature by a longer time, allowing greater disequilibrium between atmosphere and ocean. This causes larger surface flux variations, which drive larger precipitation variations. Moist convective processes are responsible for communicating the tropospheric temperature signal to the surface in this model.

Preliminary observational analysis suggests that the above mechanism may be applicable to interpreting interannual climate variability in the remote Tropics. In particular, it offers a simple explanation for the gross spatial structure of the observed surface temperature response to ENSO, including the response over land and the lack thereof over the southeast tropical Atlantic and southeast tropical Indian Oceans. The mechanism predicts that the air-sea humidity difference variation is a driver of ENSO-related remote tropical surface temperature variability, an addition to wind speed and cloudiness variations that previous studies have shown to be important.
\end{abstract}

\section{Introduction}

The connection between interannual variations in tropical tropospheric temperature (hereafter TT) and ENSO is well established (e.g., Horel and Wallace 1981; Pan and Oort 1983; Newell and Wu 1992; Yulaeva and Wallace 1994, hereafter YW94; Soden 2000). YW94 show in particular that monthly mean 1000-200-mb tropospheric temperatures [as measured by the microwave sounding unit (MSU) channel 2 (Spencer and Christy 1992)] averaged over the global tropical strip $20^{\circ} \mathrm{S}-$ $20^{\circ} \mathrm{N}$ clearly show the warming influence of the 1982/

\footnotetext{
* Joint Institute for the Study of the Atmosphere and the Ocean/ Climate Impact Group Contribution Number 865.

Corresponding author address: J. C. H. Chiang, JISAO, University of Washington, Box 354235, Seattle, WA 98195-4235.

E-mail: jchiang@atmos.washington.edu
}

83 and 1986/87 El Niño and the anomalously warm period in the first half of the 1990s. The magnitude of this warming is around $0.5-1{ }^{\circ} \mathrm{C}$ for strong El Niño years. Figure 1 shows this same analysis updated to December 1999, showing in addition the significant response for the 1997/98 El Niño. This warming occurs almost uniformly over the global tropical strip (as shown by Fig. 4 of YW94).

The reason for this uniform distribution is well understood. The tropical free atmosphere cannot maintain horizontal pressure gradients, and temperature anomalies become uniformly distributed over the global Tropics on timescales of a month or two (Charney 1963; Schneider 1977; Held and Hou 1980; Wallace 1992; YW94; Sobel and Bretherton 2000, hereafter SB00). YW94 showed the warming's close linkage to increased convection in the eastern equatorial Pacific. Lag correlations between Niño-3 SST, tropical-mean SST, and tropical-mean tropospheric temperature show that Niño- 


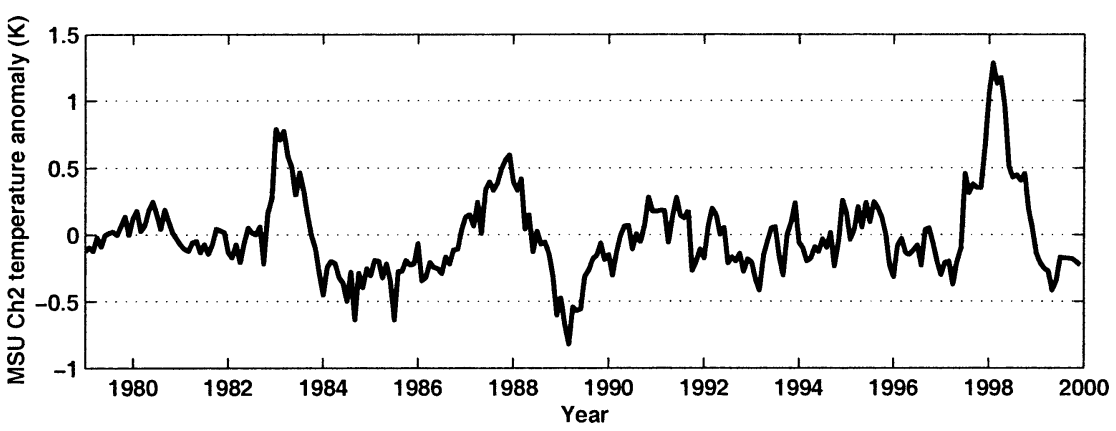

FIG. 1. MSU channel-2 temperature averaged over the tropical strip from $20^{\circ} \mathrm{S}$ to $20^{\circ} \mathrm{N}$.

3 leads both the tropical mean SST and TT, implying that the tropical Pacific predominantly controls the interannual variability of tropical TT (e.g., Pan and Oort 1983; Sobel et al. 2002).

What is the effect of this warming on the variability of other tropical climate variables outside the Pacific (hereafter the remote Tropics)? Deep convective quasi equilibrium (Arakawa and Schubert 1974) maintains that convection is always sustained so that the convective available potential energy (CAPE) variations remain small compared to the large-scale forcing of CAPE. In the limit of zero convective adjustment time [strict quasi equilibrium (SQE; Emanuel et al. 1994)], the virtual temperature profile is precisely locked to the boundary layer equivalent potential temperature $\left(\theta_{e}\right)$ through a moist adiabat, in such a way as to keep the CAPE variation to zero. According to SQE, an externally caused perturbation of TT caused by ENSO leads to an instantaneous adjustment of the boundary layer $\theta_{e}$. Since boundary layer $\theta_{e}$ is closely tied to SST through surface flux, Brown and Bretherton (1997) suggested this mechanism as an explanation for the observed increase in sea surface temperature over the tropical Atlantic and Indian Oceans during El Niño years. YW94 also suggested that much of the large-scale interannual variability in temperature of the remote tropical ocean and land surface is interpretable as a passive thermodynamic response to ENSO.

These observations suggest that it may be useful to consider the response of other atmospheric variables and SST to imposed TT changes above the boundary layer as a one-dimensional problem. We use a single-column model to study the remote tropical vertical column's adjustment to imposed TT perturbations above the boundary layer. Since TT is prescribed, the precipitation and vertical velocity are determined by model physics (SB00). This is as opposed to the more standard approach of specifying the vertical velocity or vertical advective tendencies, which, unlike the present approach, strongly constrains the precipitation. We include a dynamically passive ocean mixed layer so that the SST can vary in response to the atmospheric temperature and humidity variations. Our model is crude in some respects-for example, it omits cloud radiative feedbacks and the effect of horizontal moisture gradients on the simulated moisture convergence, and handles the boundary layer in an unsophisticated way-so no great quantitative precision is claimed. However, we believe that key aspects of the response to ENSO-caused TT variations are captured at least in a qualitative way.

The assumption of an externally imposed TT perturbation is at the heart of our method, and we devote the next section towards justifying this assumption. In particular, we expand on the spatial and temporal characteristics of tropical tropospheric warming due to ENSO, which is an interesting physical phenomenon in its own right. Then, an idealized TT variation is then applied to the single column radiative-convective model in order to simulate the adjustment process over convective regions of the remote tropical oceans. A simple conceptual argument is proposed to explain the model response to TT perturbations. We discuss the implications of our results to understanding the nature of the remote tropical response to ENSO; and show, through comparison with observations, the plausibility of our mechanism to interpreting observed features of the tropical ENSO teleconnection. Finally, we discuss the TT mechanism in the context of previous studies of the tropical ENSO teleconnection.

\section{ENSO control over tropical tropospheric temperature variability}

\section{a. Theoretical considerations}

The justification used by SB00 in their single-column model study of tropical precipitation is that a single column, by itself, cannot change the tropospheric temperature above the boundary layer since, being nearly horizontally uniform, the TT profile is a property of the global Tropics. This uniformity comes about as a consequence of geostrophic adjustment under a small Coriolis parameter near the equator (e.g., Charney 1963; Sobel et al. 2001), and has been used as a simplifying assumption in many idealized models of the tropical atmospheric circulation (e.g., Lindzen and Nigam 1987; Satoh 1994; Pierrehumbert 1995; Fang and Tung 1996; Miller 1997; Clement and Seager 1999; SB00). For the ENSO variability problem, we additionally have the 

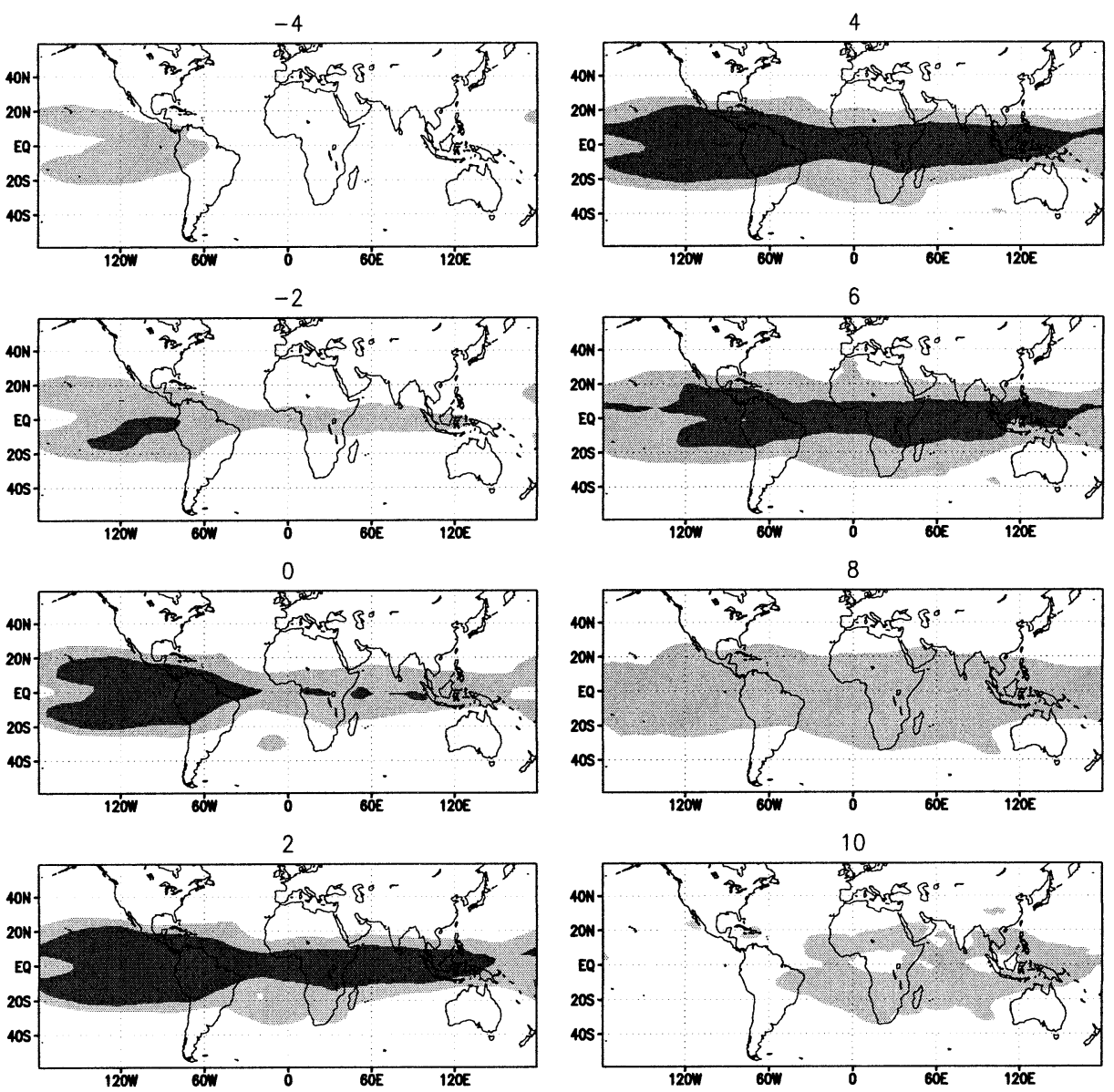

FIG. 2. Lag correlation between the Niño-3 index (SST anomalies averaged between $5^{\circ} \mathrm{S}-5^{\circ} \mathrm{N}$, and $150^{\circ}-90^{\circ} \mathrm{W}$ ), and MSU channel-2 temperatures for 1979-99. Light shading is for $0.3<r<0.6$, and dark is $r>=0.6$. The number above each panel indicates the lag or lead in months: a -2 implies MSU channel 2 leads Niño-3 by 2 months.

property that ENSO, as expressed by SST anomalies in the central and eastern tropical Pacific, controls interannual TT variations (YW94; Sobel et al. 2002). That the TT variations can be considered externally imposed in the tropical Atlantic (for example) follows from the facts that ENSO is generated by coupled ocean-atmosphere interactions (in which ocean dynamics play a major role) in the Pacific (Zebiak and Cane 1987), and that the tropical Pacific, being a larger basin with stronger and more variable deep convection, exerts the dominant control on tropical TT variability.

The perturbation vertical TT profile is set by the vertical structure of anomalous convection in the ENSO region. As discussed in Wu et al. (2001), the depth of convection in the Pacific source region aids in the rapid tropical redistribution of TT to the rest of the Tropics, since the heating projects onto vertical modes with fast horizontal propagation speeds.

\section{b. Observational evidence}

We document the transient nature of the MSU channel-2 TT response to ENSO. A lag correlation between the ENSO index Niño-3 (defined as the SST anomaly averaged over $5^{\circ} \mathrm{N}-5^{\circ} \mathrm{S}$, and $150^{\circ}-90^{\circ} \mathrm{W}$ ), and monthly mean 1000-200-mb tropospheric temperatures as measured by MSU channel 2 (Spencer and Christy 1992) is shown in Fig. 2 [see Sobel et al. (2002) for a closely related analysis]. The response can be divided into three phases: growth $[-5$ to 0 months (note that negative months are months where MSU leads Niño-3)], mature $(+1$ to +5 months), and decay ( +6 months and onward). In the growth phase, significant warming $(r>$ 0.3 ) occurs in the eastern and central Pacific, exhibiting the characteristic "dumbbell shape" (YW94) straddling the equator. After the establishment of the dumbbell shape, an equatorial warm "tongue" develops and extends westward from the eastern equatorial Pacific. The equatorial tongue has the appearance of a free Kelvin wave front, though this cannot be confirmed given the coarse temporal resolution of the dataset used [Bantzer and Wallace (1996) found a similar feature associated with the Madden-Julian oscillation using pentad-resolution MSU channels 3 and 4, which they interpreted as a Kelvin wave front associated with the switch-on of 
an equatorial heat source]. In the mature phase, the warming extends poleward in both hemispheres. The maximal extent of the meridional expansion to around $30^{\circ} \mathrm{N}$ and $\mathrm{S}$ is reached in this phase. Uniformly high correlation $(r>0.6)$ exists throughout the global tropical strip except for the western Pacific; the maximum correlation averaged over the remote Tropics $\left(60^{\circ} \mathrm{W}-\right.$ $90^{\circ} \mathrm{E}$ and $20^{\circ} \mathrm{S}-20^{\circ} \mathrm{N}$ ) occurs when the MSU field lags Niño-3 by 4 months. The decay phase show the gradual disappearance of the dumbbell shape in the central and eastern equatorial Pacific and followed by the rest of the tropical strip. The signal disappears over the Atlantic, Indian, and western Pacific Oceans around +11 months.

Pan and Oort (1983) show a similar calculation, but using upper-air observations from a global radiosonde network. Our results generally confirm their findings, although their results do not show the fast propagation of equatorial TT from the eastern equatorial Pacific.

The lag correlation results reinforce the following points: a) the tropical Pacific is the source region for TT variations, b) the signal spreads rapidly throughout the entire Tropics, and c) ENSO dominates the interannual variability of remote tropical TT. Without ENSO, the variance in monthly mean remote tropical TT anomalies would be only around half of what is currently observed (Christy and McNider 1994). While our working assumption is that ENSO dominates TT variations at all tropical locations, the spatial distribution of the above lag correlation suggests that in reality this assumption works best near the equator, and becomes progressively less valid farther away from the equator.

\section{Simulations with a single-column model}

\section{a. Single-column model}

The single-column model is based on the radiativeconvective model of Rennó et al. (1994). It uses the convective scheme by Emanuel (1991) and the radiation scheme of Chou et al. (1991). The current model includes vertical advection by the large-scale flow using an upwind differencing scheme. No explicit vertical diffusion is used, although the upwind scheme is implicitly diffusive. The reader is referred to the original papers for details of the model parameterizations. The model vertical resolution is $50 \mathrm{mb}$ from 1000 to $200 \mathrm{mb} ; 25$ $\mathrm{mb}$ from 200 to $100 \mathrm{mb}$; and there are nine additional levels between 100 and $0 \mathrm{mb}$. The model is set to clearsky radiation conditions, so that cloud radiative feedback is not considered. While neglected cloud radiative feedbacks could potentially be quite important, in deep convective regimes there is some justification for neglecting them in the surface energy budget, since the shortwave and longwave effects of clouds in the Tropics cancel each other to a large degree (e.g., Ramanathan et al. 1989).

Following SB00, we specify the vertical temperature profile above the planetary boundary layer (PBL; set at $825 \mathrm{mb}$ ). Horizontal temperature advection is assumed negligible, a good assumption in the deep Tropics; and the temperature tendency is set to zero above the PBL in accordance with our assumption of imposed TT profile. Consequently, the temperature equation becomes a balance between diabatic heating and adiabatic cooling, and hence a diagnostic for the large-scale vertical velocity $(\omega)$. The boundary layer $\omega$ is found through linear interpolation (in pressure) from the PBL top $\omega$ to $\omega=$ 0 at the surface. The moisture equation remains prognostic, and includes a moisture convergence that is controlled by the vertical velocity diagnosed from the temperature equation. Like temperature, horizontal moisture advection is assumed negligible; its a more questionable assumption but with no easy alternative, since there is no truly correct way to model horizontal advection explicitly in a single-column model. Large-scale vertical advection of moisture is retained, which implies convergence or divergence; effectively, we assume that $\boldsymbol{\nabla} \cdot(q \mathbf{v}) \cong q \boldsymbol{\nabla} \cdot \mathbf{v}$. This will tend to exaggerate the moisture convergence feedback, since it assumes that when local forcings act to change the local humidity, the humidity of adjacent regions (from which moisture is advected) change in lockstep.

A slab ocean mixed layer of prescribed depth is used for the surface, so that the model predicts surface temperature. While the immediate physical analogy of this surface parameterization is the surface ocean, it is more generally intended as a crude proxy for processes that determine the timescale of the surface temperature response. In particular, land (small thermal inertia) can be crudely represented by a very shallow mixed layer; and locations over the surface ocean with strong downgradient ocean heat transport can be crudely represented by a very deep mixed layer.

The imposed basic state vertical profile of temperature is derived from annual average (1979-99) fields from National Centers for Environmental Prediction-National Center for Atmospheric Research (NCEP-NCAR) reanalyses (Kalnay et al. 1996; hereafter, simply the reanalyses) over the global Tropics from $16.25^{\circ} \mathrm{S}$ to $16.25^{\circ} \mathrm{N}$. Radiation is set to annual- and diurnal-average conditions, and the geographical position at $10^{\circ} \mathrm{N}$. The solar constant is set to $1382 \mathrm{~W} \mathrm{~m}^{-2}$, and $\mathrm{CO}_{2}$ levels to $330 \mathrm{ppm}$. We fix surface wind speed at $6 \mathrm{~m} \mathrm{~s}^{-1}$, which is close to the annual-mean tropical ocean surface wind speed (between $16^{\circ} \mathrm{N}$ and $\mathrm{S}$ ) as computed using the Da Silva et al. (1994) dataset.

The perturbation experiments are done for three model mean-state climates: precipitation $(P)>$ evaporation $(E), P<E$, and no convection. They represent (respectively) three distinct regions of the tropical atmosphere: a deep convection regime (mean ascent), a shallow convection regime (mean descent), and a stratocumulus regime with a stable lower troposphere. The different mean states are obtained by modifying the albedo (see Table 1). This controls the shortwave radiative 
TABLE 1. Single-column model parameter settings and equilibrium results for $P>E$ regime, $P<E$ regime, and no convection regime.

\begin{tabular}{lccc}
\hline \hline & $P>E$ & $P<E$ & $\begin{array}{c}\text { No } \\
\text { convection }\end{array}$ \\
\hline Lat $\left({ }^{\circ}\right)$ & 10 & 10 & 10 \\
Mixed layer depth (m) & 40 & 40 & 40 \\
Albedo & 0.12 & 0.35 & 0.47 \\
Precipitation $(P)\left(\mathrm{mm} \mathrm{day}^{-1}\right)$ & 9.67 & 2.21 & 0.69 \\
Evaporation $(E)\left(\mathrm{mm} \mathrm{day}^{-1}\right)$ & 5.64 & 3.61 & 1.13 \\
$P-E\left(\mathrm{~mm} \mathrm{day}^{-1}\right)$ & 4.03 & -1.40 & -0.44 \\
SST $\left({ }^{\circ} \mathrm{C}\right)$ & 28.58 & 26.51 & 16.94 \\
CAPE $\left(\mathrm{J} \mathrm{kg} \mathrm{kg}^{-1}\right)$ & 1330.6 & 392.3 & 0 \\
1000-mb $\theta_{\mathrm{e}}(\mathrm{K})$ & 348.6 & 344.4 & 315.6 \\
\hline
\end{tabular}

energy flux into the ocean mixed layer, which exerts a dominant control on the mean SST. SST controls nearsurface temperature and humidity, which (since TT is fixed) control the stability of the atmosphere to deep convection. A lower albedo thus leads to more rainfall, and vice versa.

The model time step is $10 \mathrm{~min}$. In all cases, the model reaches a steady state by day 500. Table 1 lists the parameters chosen for each basic state, and also the values for the precipitation, surface evaporation, $\theta_{e}$, CAPE, and SST at day 500. The CAPE computed here is pseudoadiabatic, and computed from all model grid points between the lifted condensation level (LCL) and level of neutral buoyancy.

\section{b. Perturbation temperature profile}

The ENSO-related perturbation vertical temperature profile applied to the model was obtained through empirical orthogonal function (EOF) analysis of reanalyses anomalous monthly mean 200-750-mb temperatures averaged over all longitudes and $16.25^{\circ} \mathrm{S}-16.25^{\circ} \mathrm{N}$. The dominant principal component (PC) explains $96 \%$ of the total variance, and its expansion coefficients are essentially the tropical strip MSU channel-2 TT shown in Fig. 1 (the linear correlation coefficient between the two time series is 0.95). We obtain the vertical perturbation temperature profile through regression of these normalized expansion coefficients on the same reanalyses TT data averaged over all longitudes and $16.25^{\circ} \mathrm{S}-$ $16.25^{\circ} \mathrm{N}$, at all vertical levels from 800 to $5 \mathrm{mb}$. The profile (Fig. 3, thick solid line) shows column-wide warming/cooling with the maximum just below $200 \mathrm{mb}$ and linearly decreasing to about $50 \%$ of its $200-\mathrm{mb}$ amplitude at $800 \mathrm{mb}$, qualitatively consistent with a moist-adiabatic vertical structure. Above $200 \mathrm{mb}$, the amplitude decreases and changes sign until it reaches a minimum around $50 \mathrm{mb}$, before increasing again above $50 \mathrm{mb}$.

Is the profile in Fig. 3 representative of the ENSOrelated perturbation TT profile over the remote Tropics? The theoretical considerations in section 2 a suggest that it should be so, since if TT is horizontally uniform at

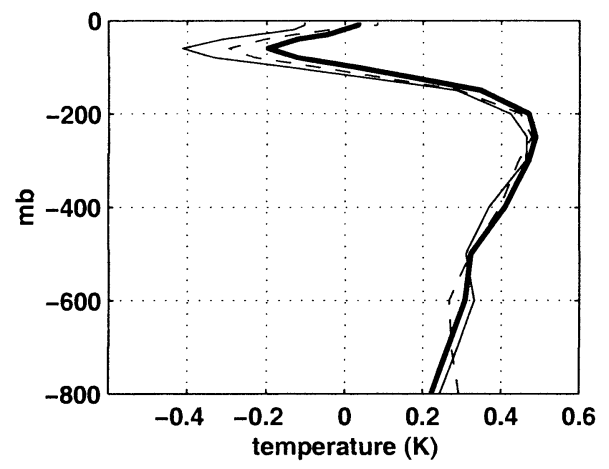

FIG. 3. The perturbation TT profile applied to the single-column model is the thick solid line (see section $3 \mathrm{~b}$ for description of the calculation). The same calculation but using only the tropical Atlantic data $60^{\circ} \mathrm{W}-10^{\circ} \mathrm{E}$ (thin solid line), and tropical Indian Ocean data $40^{\circ}$ $100^{\circ} \mathrm{E}$ (thin dashed line) shows that the profiles are similar even when the calculation is applied over restricted domains away from the Pacific.

all levels (above the PBL) the vertical profile of TT must be similarly uniform. To show this, we recomputed the profile using the same technique above, but using data limited to the tropical Atlantic $60^{\circ} \mathrm{W}-10^{\circ} \mathrm{E}$ (Fig. 3, thin solid line), and tropical Indian $40^{\circ}-100^{\circ} \mathrm{E}$ (Fig. 3, thin dashed line). Both profiles resemble the profile computed over the entire Tropics. Furthermore, their expansion coefficients (not shown) are basically the same (the linear correlation coefficient $r=0.9$ between the entire Tropics and tropical Atlantic time series; and $r=0.92$ between the entire Tropics and tropical Indian time series).

\section{c. Model results}

1) $P>E$ REGIME

After a model spinup period of 500 days, the perturbation temperature profile is applied to the model in time with a sine wave of amplitude 3 (so the maximum perturbation is $3 \sigma$ away from the observed mean standard deviation, and comparable to the largest ENSO events). We use a perturbation period of two yr, as the typical ENSO episode (a warming in the first boreal winter followed by a slight cooling in the next winter) lasts about that long. We ignore the first perturbation cycle since it is usually different from subsequent cycles due to transient adjustment. By the second cycle the model response has approximately equilibrated.

Figures $4 \mathrm{a}-\mathrm{c}$ show the model behavior for precipitation and evaporation, SST and CAPE, respectively, for the "realistic" 40-m mixed layer depth. The 500mb imposed TT (Fig. 4d) is also shown for reference. The precipitation cycle (Fig. 4a) is approximately sinusoidal, and roughly in quadrature with imposed TT. The precipitation variation is just under $4 \mathrm{~mm} \mathrm{day}^{-1}$ peak to peak for a mean precipitation of $\sim 10 \mathrm{~mm} \mathrm{day}^{-1}$. Note that evaporation variations $\left(\sim 0.75 \mathrm{~mm} \mathrm{day}^{-1}\right)$ are much smaller. This implies that most precipitation var- 


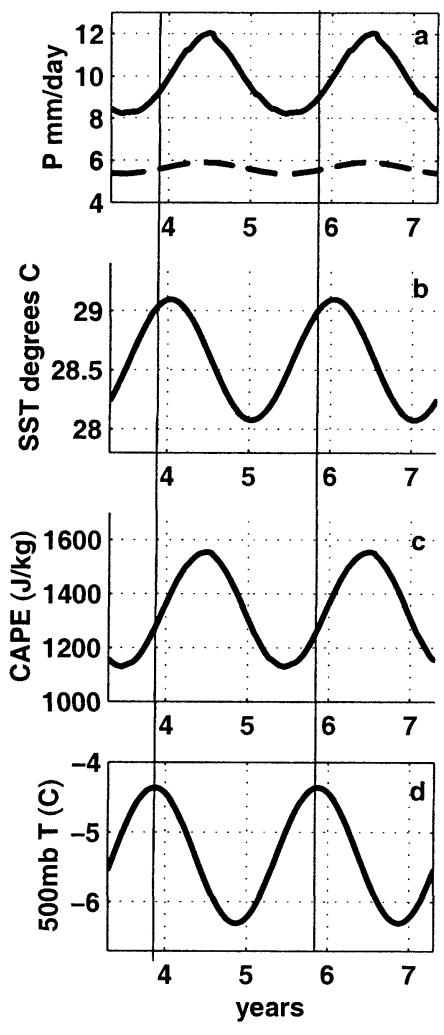

FIG. 4. $P>E$ model response to imposed TT perturbations, for an MLD of $40 \mathrm{~m}$. (a) Precipitation (solid line) and evaporation (dashed line), (b) SST, (c) CAPE, and (d) imposed 500-mb temperature.

iation is due to increased moisture convergence, and not evaporation. As discussed above, the moisture convergence effect is likely exaggerated due to the neglect of horizontal moisture gradients, since we expect a region with mean precipitation of $10 \mathrm{~mm} \mathrm{day}^{-1}$ to be moister than adjacent regions. The SST cycle (Fig. 4b) is also sinusoidal, and lags imposed TT by about 2 months. The peak to peak amplitude of $\sim 1 \mathrm{~K}$ is of the correct magnitude compared to observed remote tropical SST variations with ENSO. The CAPE response (Fig. 4c) is also sinusoidal, and like precipitation, also approximately in quadrature to imposed TT.

We vary the mixed layer depth (MLD) in the model to examine the sensitivity of the SST and precipitation responses to this parameter. The response time series (not shown) are all approximately sinusoidal, but differ in amplitude and phase for precipitation and SST. The phase information is given in months relative to imposed TT. If the imposed TT is

$$
\mathrm{TT}=A \sin (\pi t / 12)
$$

( $t$ is in months), then the phase is computed from

$$
\begin{aligned}
R=B \sin [\pi(t+\varphi) / 12], & \\
& -12 \text { months }<\varphi<12 \text { months, }
\end{aligned}
$$

where $\varphi$ is chosen so that $R$ has the largest positive
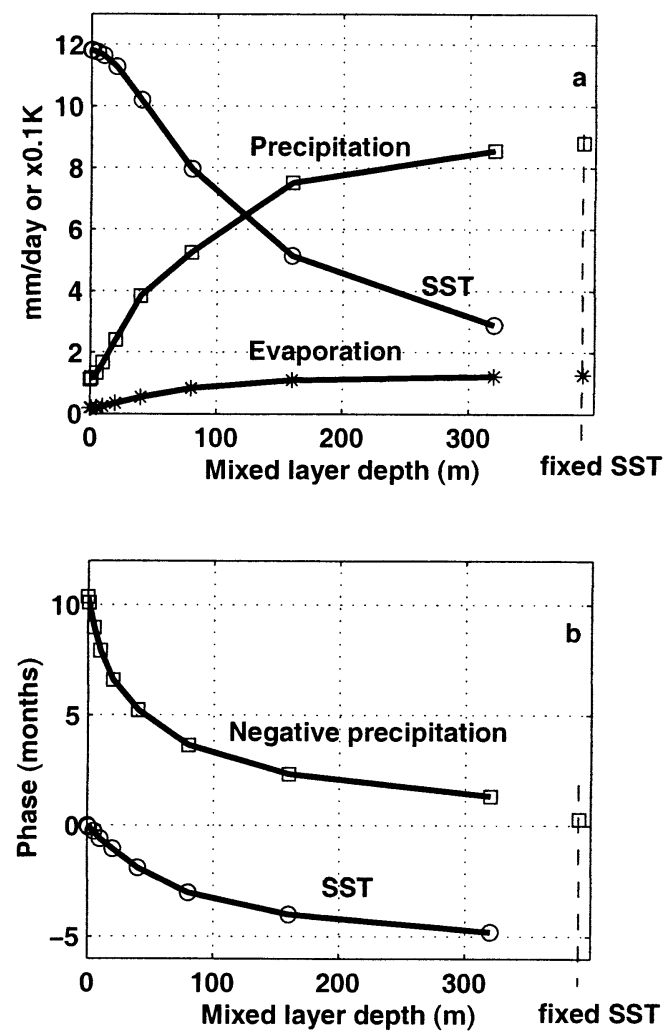

FIG. 5. $P>E$ model response to imposed TT perturbations and varying MLD. (a) Precipitation, SST, and evaporation peak to peak amplitude as a function of MLD. (b) Phase of the negative precipitation anomaly and SST anomaly relative to the imposed TT forcing, as a function of MLD.

linear correlation to the response. Figure 5 shows these response curves; note, however, that for precipitation we plot the phase of the negative of the precipitation anomaly, as we usually associate TT warming with reduced rainfall. The model precipitation and SST response to MLD is summarized as follows.

- The amplitude of precipitation response increases with increasing MLD. In particular, for a 1-m MLD the precipitation peak to peak amplitude is $\sim 1.5 \mathrm{~mm}$ day $^{-1}$. The amplitude increases rapidly and approximately linearly to $\sim 8 \mathrm{~mm} \mathrm{day}^{-1}$ for the 160 -m MLD, after which the response tails off. For the fixed SST case (infinite MLD), the amplitude is $\sim 8.5 \mathrm{~mm} \mathrm{day}^{-1}$. - The amplitude of SST response decreases with increasing MLD. The peak to peak amplitude is $\sim 1.2$ $\mathrm{K}$ for the 1-m MLD, and decreases to just less than $0.3 \mathrm{~K}$ for the 320-m MLD.

- The phase of the negative precipitation anomaly decreases with increasing MLD; in particular, for the 1$\mathrm{m}$ MLD the phase is around +10 months. The phase rapidly decreases to about +3 months for the $80-\mathrm{m}$ MLD, after which it tails off. For the fixed SST case, the negative precipitation anomaly is almost in phase with imposed TT. 


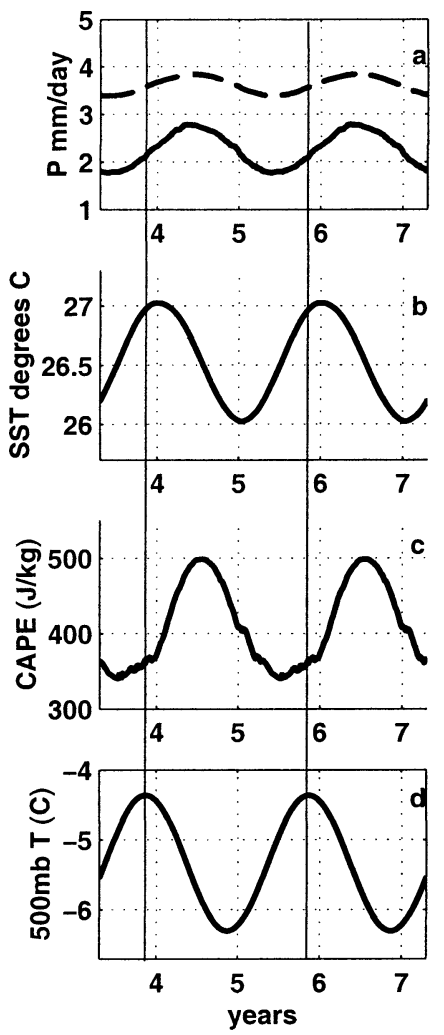

FIG. 6. Same as in Fig. 4, but for the $P<E$ case.

- The SST phase also decreases as MLD increases, though the change is not as pronounced as that for precipitation. SST is almost in phase with TT for the shallow 1-m MLD, and the phase decreases to around -3 months for the 80-m MLD, after which it tails off.

\section{2) $P<E$ REgIME}

Figure 6 is the same as Fig. 4 but for the $P<E$ regime. The variation in SST is similar to that for the $P>E$ case in both amplitude and phase; the same can also be said for the precipitation phase. The precipitation amplitude ( $\sim 1 \mathrm{~mm} \mathrm{day}^{-1}$ peak to peak) is, however, much reduced compared to the $P>E$ case $(\sim 4 \mathrm{~mm}$ day $\left.^{-1}\right)$. This is not surprising given the smaller mean precipitation in the $P<E$ case, and that total precipitation cannot be negative. Correspondingly, CAPE variations are also significantly reduced: $\sim 150 \mathrm{~J} \mathrm{~kg}^{-1}$ as compared to $\sim 400 \mathrm{~J} \mathrm{~kg}^{-1}$ for the $P>E$ case. The evaporation peak-to-peak amplitude $\left(\sim 0.5 \mathrm{~mm} \mathrm{day}^{-1}\right)$ is also reduced compared to the $P>E$ case $(\sim 0.75 \mathrm{~mm}$ day $^{-1}$ ), but the reduction is not nearly as much as for precipitation.

The similarities and differences between $P>E$ and $P<E$ regimes found for the 40-m MLD case hold up if variation with MLD is considered. Figure 7 is the same as Fig. 5 but for $P<E$. The phase variation for precipitation, and both phase and amplitude variations
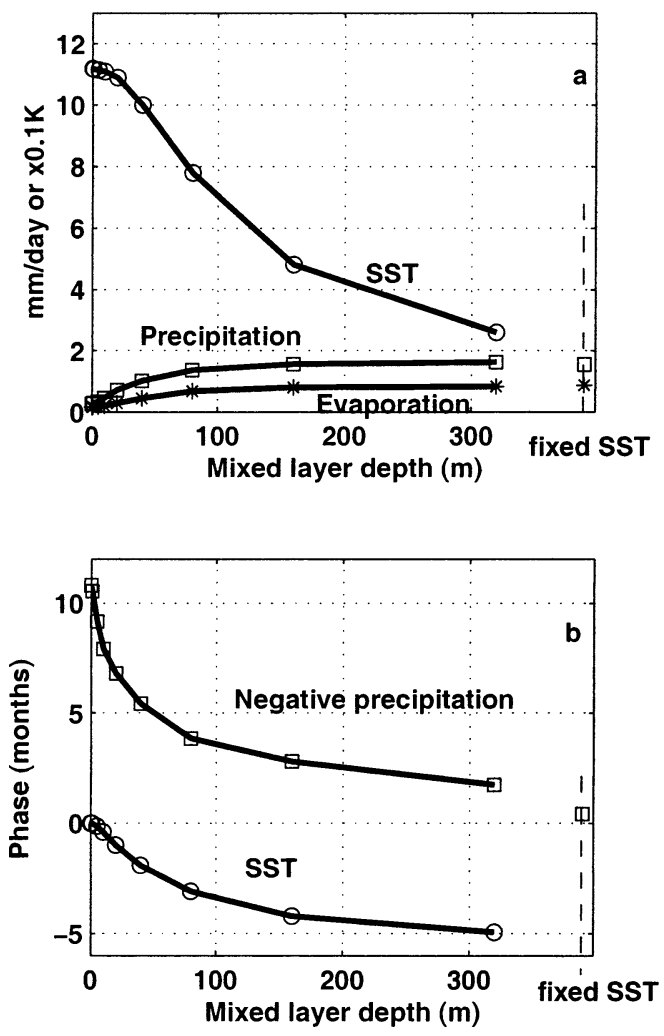

FIG. 7. Same as in Fig. 5, but for the $P<E$ case.

for SST, with varying MLD is similar to the $P>E$ regime. The major difference is in the amplitude of precipitation variations, which are reduced by a factor of $\sim 6$. So, despite the difference in the mean state between the $P>E$ and $P<E$ cases, the model responses are quite similar, except for the amplitude of the precipitation (and therefore CAPE) variations.

The model results obtained above appear robust for both $P>E$ and $P<E$ cases. The amplitude of the model response is linear with respect to the amplitude of the TT forcing. We have also repeated the TT perturbation experiments with quantitatively different $P>$ $E$ and $P<E$ basic states, with similar results.

\section{3) No-CONVECTION REGIME}

We repeat the same 40-m MLD experiment in a regime of no model convection. The significant result of this experiment (not shown) is that the SST response is significantly reduced compared to the $P>E$ and $P<$ $E$ cases. For the 1-m MLD case, the amplitude is reduced by half compared to the $P>E$ and $P<E$ cases; for the 40-m MLD, the amplitude is reduced by a factor of $\sim 6$; and for the extreme cases (MLD $>100 \mathrm{~m}$ ) the amplitude differs by an order of magnitude. With convection shut off, updrafts and downdrafts associated with convection do not occur, and exchange between the model boundary layer and free troposphere is limited 
to large-scale vertical advection and dry adiabatic adjustment. Our result here implies that it is convective downdrafts, in combination with the compensating subsidence between clouds that is also included in the convection scheme (Emanuel 1991), that is important for communicating the free troposphere signal to the surface in this model. A more sophisticated treatment of the PBL may increase the effectiveness of processes other than deep convection in accomplishing this communication, but it is likely that when deep convection is active it will be the dominant mechanism connecting the PBL to the free troposphere.

\section{Analysis of model results}

We argue that the inverse relationship between the model SST and precipitation amplitude is causally linked. If the imposed TT is perturbed, then SQE maintains that subcloud-layer $\theta_{e}\left(\theta_{e b}\right)$ will follow TT perturbations over timescales comparable to the convective timescale. However this change in $\theta_{e b}$ will change the thermal disequilibrium between the atmosphere and ocean, resulting in a change in surface turbulent energy fluxes (assuming the surface wind speed is fixed, as it is in these simulations). The turbulent fluxes must balance the surface radiative fluxes in steady state. If the radiative fluxes do not change as much as the evaporation does in response to the imposed TT change, the resulting imbalance in the surface energy budget will induce a slow change (compared to the convective timescale) in the SST, until the SST reaches a value such that the turbulent fluxes come back into balance with the radiative fluxes.

What is the timescale for SST adjustment? In the model it turns out to be a linear function of the mixed layer depth (Fig. 8). We computed the adjustment time for both the $P>E$ and $P<E$ cases by running the model to equilibrium using the extreme La Niña TT profile (in other words, the imposed TT profile is the mean TT profile subtracted by 3 times the perturbation profile shown in Fig. 3), and then suddenly switching to the extreme El Niño (mean TT plus 3 times the Fig. 3 perturbation) profile. We took the SST adjustment time to be the $e$-folding time for the model SST to adjust to the new equilibrium state. The point of Fig. 8 is that, for both the $P>E$ and $P<E$ cases, the SST adjustment timescale is much faster than the $O(1 \mathrm{yr})$ TT perturbation timescale for $O(1 \mathrm{~m})$ mixed layer depths, so for those mixed layer depths the model state is always close to equilibrium. For realistic ocean mixed layer depths, however, the SST adjustment timescale is an appreciable fraction of the TT perturbation timescale, and so the model state is continually in adjustment. We hypothesize that the model response to the ENSO TT forcing depends on the ratio of the forcing to SST adjustment timescales, and the variation in fluxes and state variables reflect the state of adjustment of the system to the imposed TT variations.

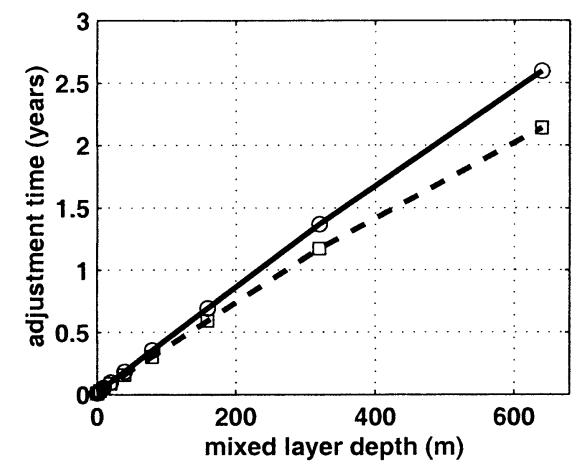

FIG. 8. The SST adjustment time as a function of MLD, for the $P$ $>E$ (solid line) and $P<E$ (dashed line) regimes. See section 4 for the derivation.

We support this hypothesis using another model sensitivity run, varying the imposed TT period but keeping the MLD fixed. Our hypothesis suggests that for faster TT variations, the ocean mixed layer will be further from equilibrium, and fluxes between the troposphere and boundary layer (i.e., convection), and between the boundary layer and ocean (i.e., evaporation), will amplify as a result. On the other hand, variation of state variables $\left(\theta_{e b}\right.$ and SST) will reduce because the system has not had sufficient time to respond. In the simulation we use a 40-m MLD and TT forcing period linearly decreasing from 3 to 0.5 yr over a 100 -model-year interval. Figure 9 shows the results for the $P>E$ regime (the $P<E$ result is qualitatively the same). The simulation confirms our hypothesis: both the precipitation and evaporation peak to peak amplitudes increase as the forcing period decreases (Fig. 9a), whereas the SST and 1000-mb $\theta_{e}$ amplitudes decrease with decreasing forcing period (Fig. 9b).

We propose this qualitative explanation for the model sensitivity to the MLD. For a shallow MLD, the SST quickly adjusts to the TT forcing, and so the SST peak follows soon after the peak in TT. It follows that surface $\theta_{e}$ is able to approximately track the TT forcing and therefore keep surface flux variations small. This keeps precipitation variations small as well, because surface flux variations control precipitation variations in this particular model (SB00). This control can be understood from gross moist stability arguments (Neelin and Held 1987; Raymond and Zeng 2000), which say that largescale vertical motion must be sustained by net input of moist static energy through the vertical boundaries of an atmospheric column, so that anomalously strong convection in steady state is driven by anomalously large surface fluxes (and/or anomalously small radiative cooling, a possibility ignored for now). The precipitation phase reflects the phase difference between the TT forcing and SST response: basically, the largest imbalance that causes positive precipitation between the two occurs when the SST anomaly is still large and the rate of decrease of TT is high. Given that both the TT forcing 

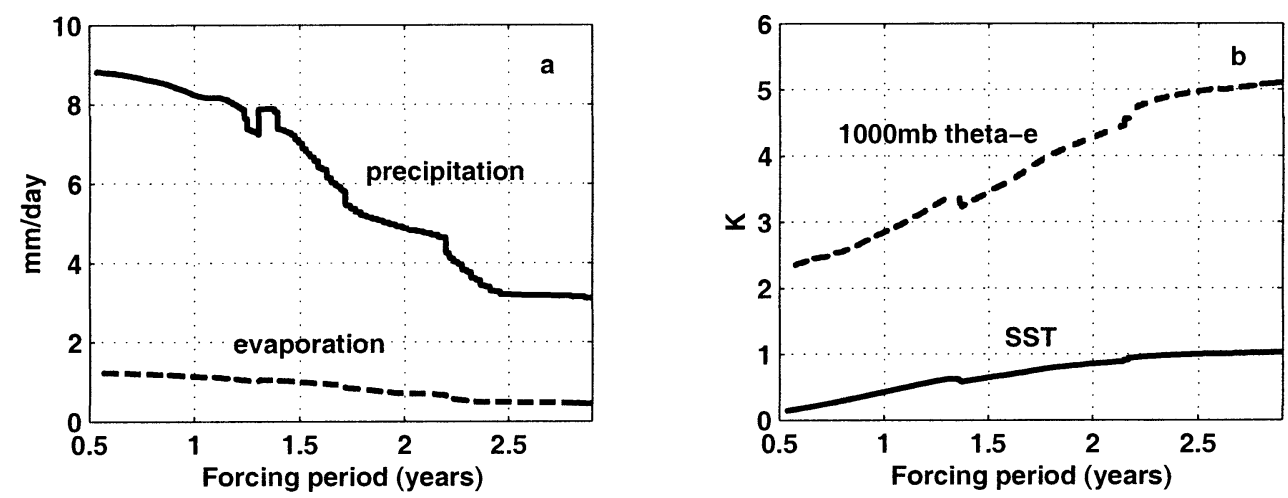

FIG. 9. The $P>E$ regime response to imposed TT with varying forcing period. The forcing was reduced from 3 to $0.5 \mathrm{yr}$ over a 100 -yr interval. The curves in (a) and (b) are peak-to-peak amplitudes, computed over a 3-yr time window. (a) Precipitation (solid) and evaporation (dashed) peak-to-peak amplitudes; (b) SST (solid) and 1000-mb $\theta_{e}$ (dashed) peak-to-peak amplitudes.

and SST response are sinusoidal, this situation occurs several months after the peak in SST (see Figs. 4 and 6). On the other hand, if the MLD is deep, the SST responds weakly and the imbalance between TT forcing and SST is large. Surface flux, and therefore precipitation, variations are large. Furthermore, because SST responds weakly, TT basically controls the phase of the precipitation variation, such that precipitation is approximately out of phase with TT.

The weakness in all these arguments is the neglect of change in the radiative cooling rate; our argument holds for the present model because the model lacks cloud radiative feedbacks. Therefore, our results concerning the magnitude of the precipitation response should be regarded as uncertain. We will address this issue by adding cloud radiative parameterization in future work. Such a parameterization has already been developed in the context of this model by Bony and Emanuel (2001).

\section{Response of the remote Tropics to ENSO \\ a. Model suggestions}

What do the model results suggest with regards to how TT-mediated ENSO signals manifest themselves over the global Tropics? The first suggestion is: the response, in particular in the precipitation, of the remote tropical atmospheric column to TT warming depends strongly on the thermal inertia of the surface. We show this by forcing the model in the $P>E$ regime with the amplitude time series associated with the EOFderived vertical TT perturbation profile (Fig. 3; also see section $3 \mathrm{~b}$ ). The shape of the EOF time series is almost identical to the MSU channel-2 Tropics-averaged time series shown in Fig. 1, except that the amplitude is 3 times larger; we refer to Fig. 1 in lieu of the actual time series for future reference. The model SST and precipitation response at 1-, 40-, and 160-m MLD are shown in Figs. 10a and 10b, respectively. The SST responses for all three MLD bear resemblance to the forcing TT time series. Furthermore, the SST response amplitude decreases for increasing MLD, as expected. On the other hand, the precipitation response is varied and not readily associated with the forcing. In particular, the 1-m MLD response is small and differs qualitatively from the 40and $160-\mathrm{m}$ response. Indicative of this, the association to ENSO appears to switch sign from the 1-m MLD case to the 40- and 160-m MLD case: the simultaneous linear correlation coefficient between the ENSO index Niño-3 and 1-m MLD precipitation time series is $r=$ 0.18 ; on the other hand, the correlation between Niño3 and the 40-m MLD precipitation time series is $r=$ -0.48 .

The second suggestion is a "rule of thumb" with regards to the precipitation response. We have argued (section 4) that the further the model is from equilibrium, the larger the convection and evaporation perturbations are. In particular, given a sufficiently large thermal inertia of the surface ("sufficient" meaning that the SST adjustment timescale is larger than the TT forcing timescale), the faster TT is changed, the more the ocean and atmosphere will be out of equilibrium, and the larger the precipitation response. This is apparent in the 40- and 160-m MLD precipitation response in Fig. 10b, when compared to the TT forcing (Fig. 1); in particular, the large dips in the 40-m MLD and 160-m MLD precipitation in late 1982/early 1983 and late 1997/early 1998 are associated with steep increases in TT forcing. The dip in precipitation in late 1987/early 1988 is smaller because the TT change was more gradual; this is despite the fact that the peak TT warming in late 1987/ early 1988 is comparable to the $1982 / 83$ event.

Our third suggestion is when and where to expect the SST response. The remote SST will warm by $O(1 \mathrm{~K})$ for TT amplitudes used here, but lagged from the peak TT warming by a few months, with the delay increasing as the surface thermal inertia increases. A more significant implication is that while SST will warm in regions 
(a)

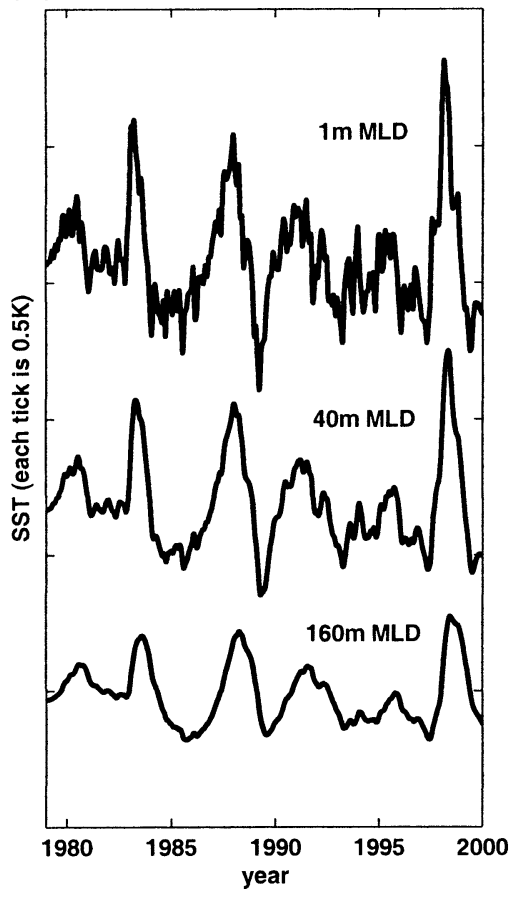

(b)

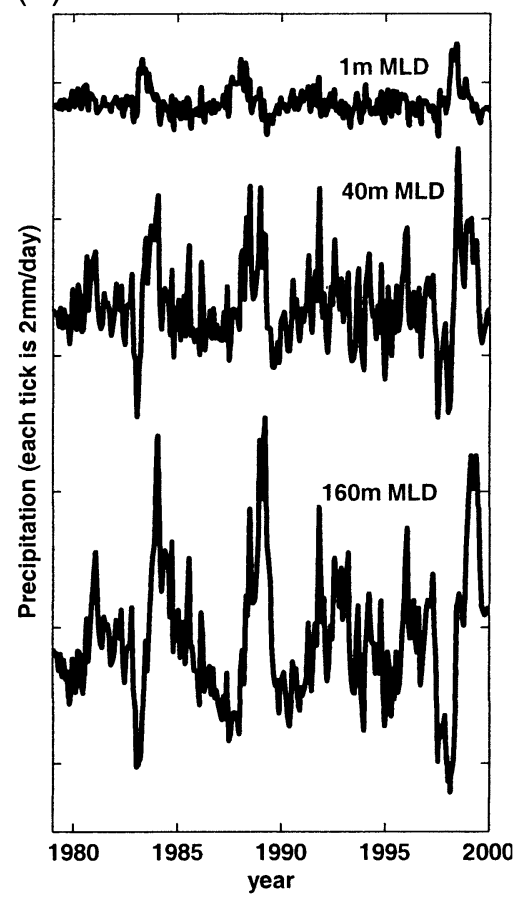

FIG. 10. Results of the single-column model with realistic TT forcing. The imposed TT amplitude is the time series associated with the TT perturbation profile shown in Fig. 3. (a) Model SST time series for the (top) 1-m, (middle) 40-m, and (bottom) 160-m MLD. The tick interval on the $y$ axis is $0.5 \mathrm{~K}$. (b) Precipitation time series for (top) $1-\mathrm{m}$, (middle) 40-m, and (bottom) 160-m MLD. The $y$-axis tick interval is $2 \mathrm{~mm} \mathrm{day}^{-1}$.

where convection occurs, the SST response will be weak in regions of no significant convection, since the surface there is effectively decoupled from the free troposphere (though again we must add a caveat due to the crude representation of the PBL in the present model; stronger entrainment of free tropospheric air into the PBL could occur in a more realistic model). The warming occurs mainly through a reduction of the latent heat flux, which is in turn a response to higher surface $\theta_{e}$.

\section{b. Comparison to observations}

We think our model results are relevant to the observed tropical ENSO teleconnection. We will examine these associations more comprehensively in the future; here, we simply try to convince the reader of the potential relevance. Figure 11a shows the linear correlation coefficient between monthly averaged 40-m MLD-model SST time series of Fig. 10a, and monthly SST anomalies taken from reanalyses over January 1979 to December 1999. Since the model SST output resembles the TT forcing and hence the ENSO signal, it is not surprising that the correlation map picks out tropical ocean and land regions known from previous studies to be linked to ENSO. The northern tropical Atlantic, the tropical Indian Ocean, and South China Sea are precisely the locations identified by Klein et al. (1999) as having significant positive association with eastern $\mathrm{Pa}-$ cific SST anomalies. Elliot et al. (2001) previously identified the weaker southwestern tropical Atlantic ENSO signal. Also in agreement with YW94, we find significant positive correlation with surface temperature (taken also from reanalyses January 1979-December 1999) over the tropical land regions $20^{\circ} \mathrm{S}-20^{\circ} \mathrm{N}$ (Fig. 11b). The 40-m MLD case is not strictly applicable over land - the 1-m MLD is likely more appropriate-but we noted before the relative insensitivity of the model surface temperature response to MLD. Figure 11a also shows that the southeastern (SE) tropical Atlantic and SE tropical Indian Ocean SSTs are not significantly associated with ENSO, in agreement with the Klein et al. (1999).

While the result of the above correlation (Fig. 11) is not surprising (since the model SST output resembles the ENSO forcing), it does point to the viability of our model and the TT mechanism in giving the correct surface temperature response. A more powerful result is that our model offers a simple explanation for the $a b$ sence of ENSO association in the SE tropical Atlantic and Indian Oceans. Figure 12 shows the annual-mean low cloud cover from the International Satellite Cloud Climatology Project (ISCCP) version D2 dataset (Rossow and Schiffer 1991), showing that these regions have large low cloud amounts (ISCCP defines low cloud as 


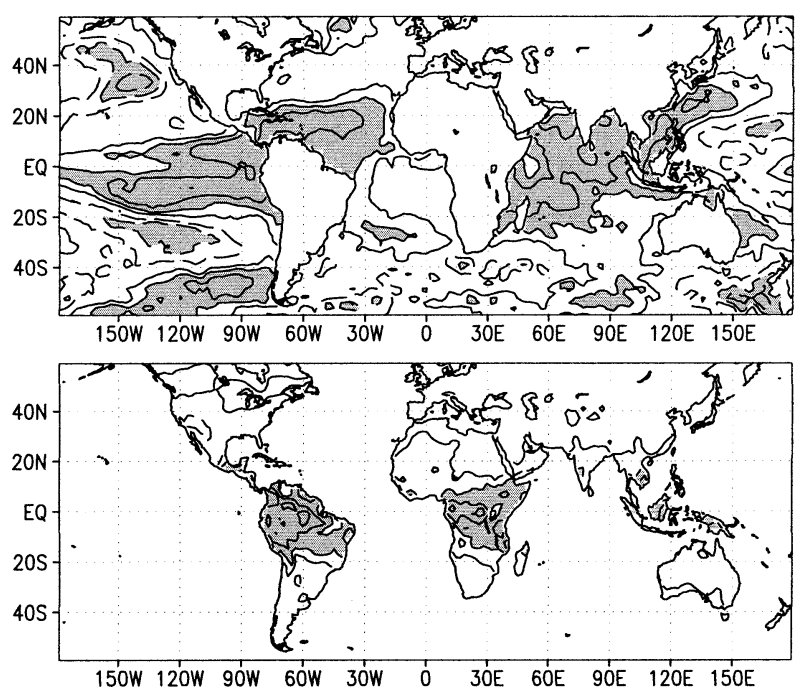

FIG. 11. Linear correlation between the 40-m MLD SST time series in Fig. 10a and NCEP-NCAR reanalysis surface temperature 197999. (top) Over oceans; (bottom) over land. The contour interval is 0.15 , and magnitudes over 0.3 are shaded. Dashed lines indicate negative correlation; the zero contour is not shown.

clouds with tops below $680 \mathrm{mb}$ ). The bulk of the low clouds in those regions are stratus and stratocumulus. Klein and Hartmann (1993) identified both these regions as ones possessing significant stratus cloud cover during all months, implying that they are regions of high static stability. This implies in turn that the surface is effectively decoupled from the free troposphere.

It is possible that the absence of the SST response might not be because there is no communication between the free troposphere and PBL, but instead because the convective response to TT forcing is counteracted by a stratus cloud response to TT. Stratus cloud cover is positively correlated to vertical static stability (Klein and Hartmann 1993), implying reduction of net downward shortwave surface flux as a result of increased stratus cloud cover with warmer TT. To test this, we incorporated the effect of stratus cloud change on surface fluxes in our model using an empirical method similar to the one used by Philander et al. (1996). In this parameterization only the surface flux is affected, and not the model atmospheric radiation budget, amounting to a flux correction for our mixed layer ocean. The perturbation in stratus low cloud cover was linearly related to the anomalous difference in potential temperature between $700 \mathrm{mb}$ and the surface based on an observed relationship between the two (Klein and Hartmann 1993); and stratus cloud cover perturbations in turn modified the model downward radiative flux, using an empirical estimate by Norris and Leovy (1994) of $1 \mathrm{~W} \mathrm{~m}^{-2}$ decrease for each $1 \%$ increase in cloud cover. We found the impact of this parameterization on our $P<E$ convective case to be small, reducing the SST peak-to-peak amplitude only by $\sim 10 \%$ for the 40 m MLD case.

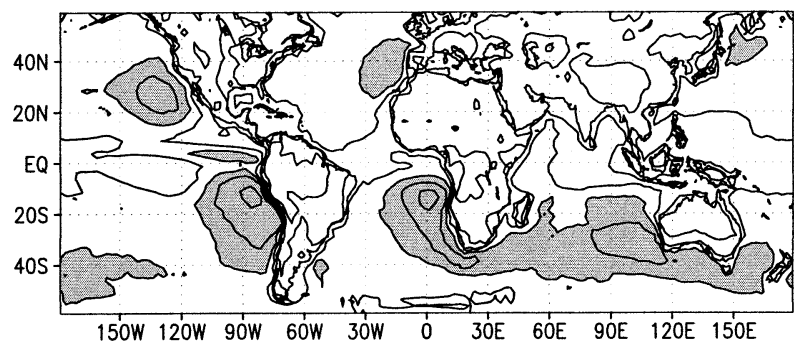

FIG. 12. Annual-mean low cloud cover fraction from ISCCP D2. The contour interval is 0.1 , and values above 0.4 are shaded.

We now focus on precipitation, correlating the monthly averaged 40-m MLD precipitation time series of Fig. $10 \mathrm{~b}$ with monthly precipitation anomalies from a global satellite precipitation dataset spanning January 1979December 1999 (Xie and Arkin 1997). If the correlation is done over all months, the correlation over the remote tropical regions, with the exception of the Indonesian subcontinent, is low $(|r| \sim 0.1)$. This is discouraging but not surprising: precipitation is highly variable on a wide range of space- and timescales, and contains much variation even on monthly timescales that is (presumably) not directly controlled by TT or SST. Additionally, the precipitation signal cannot be large unless there is significant mean precipitation in the first place. The intertropical convergence zone (ITCZ) migrates, so if there is an association at any particular location, it is likely to be strong only at specific times of the year. It implies we need to take more care with our analysis.

The tropical Atlantic has been identified (e.g., Saravanan and Chang 2000; Chiang et al. 2000, 2002; Giannini et al. 2001) as a location of significant ENSO influence through the anomalous Walker circulation. The tropical Atlantic is the most promising candidate for our proposed mechanism for several reasons. First, the tropical Atlantic is the colder and smaller of the two remote tropical ocean basins, implying that any variation in convection there is not likely to feed back significantly on TT (recall our working assumption that TT variation is externally controlled by ENSO). Second, it is close to the eastern equatorial Pacific source of anomalous convective heating, so that the TT signal (cf. Fig. 2) reaches the tropical Atlantic with minimal damping. Third, the effective surface thermal inertia in the Atlantic cold tongue region may actually be higher than what a $\sim 50-\mathrm{m}$ or so tropical ocean mixed layer might suggest, because equatorial upwelling may act to quickly damp surface temperature anomalies; recall that TTcaused precipitation anomalies increase when the surface thermal inertia increases. We focus on the JanuaryFebruary-March (JFM) period when the convective perturbation in the eastern equatorial Pacific is largest (Chiang et al. 2002), but before the tropical Atlantic SST has had time to respond. During those months, the Atlantic ITCZ is also near the equator, within the region of the strongest ENSO-related TT warming (Fig. 2). 


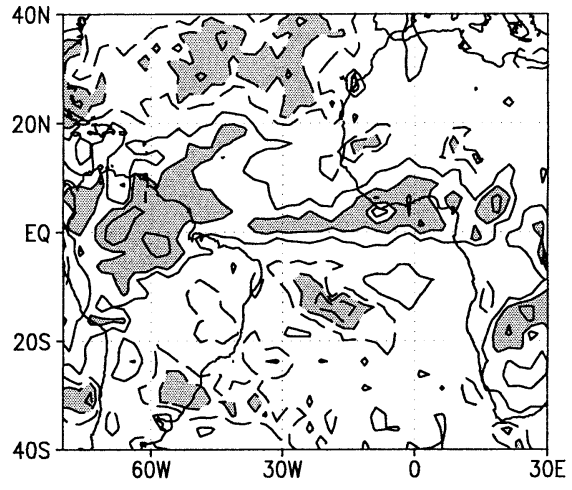

FIG. 13. Linear correlation between the JFM averaged 40-m MLD precipitation time series in Fig. 10 and Xie-Arkin (1997) global precipitation dataset JFM 1979-99. The contour interval is 0.2, and magnitudes over 0.4 are shaded. Dashed lines indicate negative correlation, and the zero contour is not shown.

Figure 13 shows the JFM correlation between the 40m MLD precipitation time series of Fig. 10b, and observed precipitation over the tropical Pacific and Atlantic. The positive correlation in the Atlantic ITCZ region, and also the neighboring Amazon, are clearly picked out. The response is not over the equator, but slightly to the north of it, reflecting the mean position of the ITCZ at that time of year. The rest of the correlation map is not as simply explained, and likely due to ENSO-related causes other than the direct TT warming effect on precipitation. In particular, the negative correlation in the north and south subtropical Atlantic may be associated with the increased baroclinicity there as a result of jet stream strengthening (YW94).

The direct evidence for TT influence on remote precipitation is not as convincing as that for SST. In particular, the sizable response over the Amazon is surprising given that land surfaces are typically thought to have small thermal inertia. It is possible that adding the currently missing physics in our model (see section 6b for a discussion) may augment the TT signal to produce a larger precipitation response over land. A more thorough observational analysis is also warranted to take into account the seasonality and variability of the remote precipitation, and the nature of the remote surface. However, we think there is enough evidence to suggest plausibility of the TT mechanism to significantly affect remote precipitation variability.

\section{c. The TT mechanism in the context of previous tropical ENSO teleconnection studies}

Previous observational studies of the remote tropical response to ENSO [e.g., Curtis and Hastenrath 1995; Klein et al. 1999 (and references therein); Yu and Rienecker 1999] focused on the causes of SST change in the remote tropical oceans. In general, these studies concluded that changes in latent heat flux due to surface wind speed changes and/or solar radiation due to change in cloud cover generate remote SST anomalies. Surface heat flux change due to change in surface temperature and specific humidity (hereafter $T-q$ changes) has thus far not been shown to play a role. However, current historical records of observational surface flux are too inaccurate for budget studies; consequently, while wind speed and cloud cover can be shown (as in the abovecited studies) to be correlated with SST change, we are aware of no budget analysis that shows quantitatively that these influences are much larger than the mechanism discussed here involving $T-q$. Furthermore, latent heat flux change caused by boundary layer $T-q$ change is difficult to detect observationally for two reasons: (i) boundary layer $T-q$ are highly correlated to surface SST at monthly timescales because of fast turbulent and convective processes linking the surface to the PBL (e.g., Betts and Ridgeway 1989), making cause and effect difficult to assess; and (ii) the fact that the surface fluxes respond strongly to $T-q$ perturbations will keep those perturbations small even if their effect on the fluxes is large. A typical $10 \mathrm{~W} \mathrm{~m}^{-2}$ anomaly in latent heat flux requires a surface-air humidity difference anomaly of around $0.4 \mathrm{~g} \mathrm{~kg}^{-1}$ (estimated from the bulk formula with standard coefficients and $6 \mathrm{~m} \mathrm{~s}^{-1}$ wind speed), which is the same magnitude as an estimated mean random error of $1.1 \mathrm{~g} \mathrm{~kg}^{-1}$ for the marine $10-\mathrm{m}$ specific humidity measurements from voluntary observing ships (Kent et al. 1999).

However, flux budget calculations can be done with general circulation model (GCM) studies. In this regard, the recent comprehensive atmospheric GCM study by Saravanan and Chang (2000, p. 2186) lends support for a significant role for $T-q$ : "Our analysis ... show[s] that changes in the wind speed and changes in the airsea temperature difference can both contribute to the heat flux anomalies. This conclusion is somewhat different from other studies of surface heat flux variability in the Tropics, which tend to focus only on the effect of wind speed changes on the latent and sensible heat flux." The atmospheric GCM-mixed layer ocean ENSO teleconnection study by Lau and Nath (2001) also shows that surface air temperature changes lead SST in the northwestern tropical Atlantic (site E of Fig. 7e in their paper), suggesting a significant role for $T-q$, although those authors do not report the strength of this effect relative to wind speed and cloudiness change.

In lieu of direct observational evidence, we appeal to the combination of potential explanatory power and simplicity offered by the mechanism proposed here. Using straightforward physical reasoning (weak horizontal TT gradients, convective quasi equilibrium) in a onedimensional context, it can explain the gross large-scale spatial features of the ENSO-related surface temperature response over both tropical oceans and land (note that the observational studies mentioned above do not address mechanisms for the land response). Cloud-cover feedbacks can actually be straightforwardly included under our approach once we include a parameterization 
of these effects in the model. Wind speed changes, on the other hand, are location specific and not derivable from a one-dimensional argument. Because of this, it is not simple to show detailed spatial correlation between wind speed change and SST change.

The causes of surface temperature response to ENSO over the remote tropical regions remain an open question to be decided ultimately by more accurate surface flux measurements. It is likely that wind speed and cloud cover are significant components of this variability. We propose additionally, based on our model results and in agreement with Saravanan and Chang (2000), that the $T-q$ effect is also important. The relative importance of each mechanism may depend on region: the TT mechanism will have the strongest effect near the equator where the ENSO-caused TT signal is strongest and the presence of convection most effectively mediates the signal to the surface. The wind speed mechanism may work best in the trade wind region (this is certainly the case for SST variability for the north tropical Atlantic). We are uncertain where cloud effects will be strongest, though the study by Klein et al. suggests that they are most effective in the regions of deep convection.

\section{Summary and discussion}

\section{a. Summary}

Interannual tropical tropospheric temperature (TT) variations are dominated by ENSO. We study its potential impact on the remote Tropics by imposing TT variations on a single-column model coupled to a slab ocean mixed layer, and investigating its response. This approach is based on assumptions that ENSO-caused TT anomalies are horizontally uniform, and there is no significant feedback on TT by the remote tropical response. We examine the model response to the variations under $P>E, P<E$, and no-convection mean conditions, and test model sensitivity to varying ocean mixed layer depth.

Experiments on the 40-m MLD single-column model using a 2 -yr period sine wave TT perturbation showed that the model precipitation and surface temperature response resembles the forcing but with significant phase shift. In particular, the SST maximum occurs 2 months following the peak TT. The size of the response to TT forcing (forcing magnitude comparable to the largest ENSO events) is significant in climate terms: SST response is $O(1 \mathrm{~K})$, and precipitation amplitude is a significant fraction of the total mean precipitation. With varying MLD, the phase and amplitude of both the SST and precipitation responses change markedly: the SST amplitude decreases and phase shift increases with increasing MLD; and the precipitation amplitude increases and phase shift also increases with increasing MLD. In a regime with no significant convection, the model SST response is an order of magnitude smaller than the cases over convective regimes. The implication is that com- munication between the free troposphere and boundary layer/surface in this model is brought about predominantly by moist convection.

We hypothesize that the timescale of SST adjustment relative to the TT forcing timescale controls the model sensitivity to MLD. A larger heat storage capacity for the ocean implies that SST takes longer to come to equilibrium with the imposed TT forcing. The more the SST and boundary layer are out of equilibrium with the free troposphere, the larger the fluxes between them (meaning convection and evaporation). A simulation in which we change the period of the TT forcing, keeping MLD fixed, confirms this hypothesis.

Our results lead to these suggestions with regards to finding TT-related ENSO signals in the remote Tropics: (a) the amplitude and phase of the SST and precipitation response depend on the surface thermal inertia; (b) the faster the rate of TT change ( $\sim$ anomalous convection in the central and eastern equatorial Pacific), the larger the remote precipitation response; and (c) the TT signal propagates to the surface only in regions of (deep or shallow) convection.

We show evidence that the TT mechanism is applicable to observed SST and precipitation variability in the Tropics outside the ENSO region. Given observed TT forcing for 1979-99, the model produces SST variations resembling those over tropical ocean regions known to be linked to ENSO. The model January-February-March (JFM) averaged precipitation response is correlated to JFM precipitation anomalies in the tropical Atlantic, in agreement with previous studies that argue for a linkage between ENSO and precipitation there via the anomalous Walker circulation. Furthermore, the TT mechanism offers a simple explanation for the lack of SST response over the tropical SE Atlantic and tropical SE Indian Oceans: that the stable lower troposphere (as evidenced by the stratus cloud decks) precludes the surface and boundary layer from being linked to the free troposphere by convection.

Previous observational studies of the ENSO teleconnection have shown that variations in cloud cover and wind speed are significant drivers of the ENSO-related remote tropical SST variability. No observational evidence has yet been shown for a role for air-sea temperature and humidity difference changes as predicted by the TT mechanism. However, observed marine fluxes are known to have significant uncertainties; and recent GCM studies have shown a role for temperature and humidity difference to drive SST variability. In lieu of direct observational evidence, we appeal to the combination of potential explanatory power and simplicity offered by the TT mechanism to argue its relevance in remote tropical climate variability.

\section{b. Discussion}

There are several potentially important processes that we have purposefully simplified or neglected in our 
study, and we summarize them here. ENSO-related cloud variations may alter the TT-forced response through changing the surface and top-of-atmosphere radiative balance. There is some cancellation of surface radiative flux changes due to change in deep convection from the shortwave and longwave components (e.g., Ramanathan et al. 1989); however, this may not be the case in shallow convective and stratus deck regions. In particular, stratus cloud variations may amplify through positive feedback on SST (e.g., Philander et al. 1996). We intend to repeat these experiments in the future, using a more realistic single-column model that includes cloud-radiation feedback.

Neglect of horizontal moisture advection may exaggerate the precipitation variations in our model. While quantitatively likely to be significant, in general it is difficult to see how it can change the qualitative sense of the convective adjustment to imposed TT variations, unless the regions adjacent to our column (from which moisture is advected) undergo large and covarying moisture change. We have also neglected the feedback on convection through modifying the large-scale (surface) horizontal flow. Convection is thought to drive large-scale circulation in the Tropics (e.g., Gill 1980), and which in turn potentially feeds back on itself in several ways: (a) through surface evaporation ("windevaporation feedback"; Neelin et al. 1987); (b) through SST via ocean dynamical processes (upwelling; mixed layer depth change; Ekman or geostrophic transports; or thermocline displacement); and (c) through changes in horizontal moisture advection.

We have shown that the surface is important to how the atmosphere responds to TT perturbations. Clearly, the ocean is not just a slab mixed layer as is assumed in this study. Variations in mixed layer depth changes the thermal inertia of the ocean surface, sometimes drastically, on seasonal and interannual timescales. Ocean heat transport (OHT) processes may damp surface fluxgenerated SST anomalies. The damping effect of these OHT processes may mean that the effective mixed layer depth is deeper than the typical $\sim 40 \mathrm{~m}$ we assumed as typical for the tropical oceans. As for land, the two important differences that matter to the TT mechanism are the smaller thermal inertia of land relative to the ocean, and the reduction in evaporation due to water stress. We have already shown the sensitivity of the model response to surface thermal inertia (section 5). Water stress over land means that cooling of the surface by evaporation is far less than over the ocean, and the surface temperature response will be larger. Feedback processes may also come into play: less convection means a drier surface, and hence less evaporation and therefore convection. On the other hand, a drier surface is also a warmer surface, and monsoon flows driven by the surface temperature contrasts may act against the positive land-evaporation feedback. A realistic land parameterization is thus crucial to study the effects of
ENSO-related TT perturbations over remote tropical land regions.

Our method is predicated on the assumption that the response in the remote Tropics does not feed back onto the TT. How good is this assumption? A remote precipitation response to the ENSO-caused TT signal indicates diabatic heating changes, and hence feedback on TT. For the tropical Atlantic precipitation response, we think the damping is small because the Atlantic El Niño (Zebiak 1993) — which accounts for much of the non-ENSO interannual variability of the Atlantic ITCZ-does not explain significant amounts of the tropical TT variance, implying the same for the ENSO-linked variations. On the other hand, Bantzer and Wallace (1996) show that variations in convection largely concentrated in the Indian Ocean region do significantly affect Tropicswide TT on the intraseasonal timescale, suggesting that Indian Ocean convection has the potential to feed back more effectively on ENSO-caused TT variations. The issue of feedback will be addressed in the future.

We end by discussing the interpretation of our mechanism. Much of the "atmospheric bridge" (Lau and Nath 1996) thinking of tropical ENSO teleconnections is in terms of the Walker circulation and its impact on remote tropical climate through suppression of rainfall by subsidence (e.g., Kumar et al. 1999; Goddard and Graham 1999; Chiang et al. 2000). The TT mechanism is (more or less) this Walker mechanism, just posed in a different way (our method can be viewed as the limiting case of a two-box model for zonal interactions of the tropical climate where one box is much larger than the other; it is remarkable that nature has provided us with an example of this). The problem with the traditional way of thinking is that it does not allow for more than just the qualitative statement that "rainfall is suppressed." This is because the Walker circulation is essentially a (horizontal) dynamical construct (e.g., Gill 1980) while the problem actually requires understanding the thermodynamics. When more precise questions are asked, for example-Where does the subsidence occur? How much rainfall is suppressed, and when? What is the difference in the response between ocean and land regions? What about the difference between deep convection/shallow convection/no convection regions?the value of our approach becomes self-evident.

Acknowledgments. We thank Yochanan Kushnir for his advice and encouragement throughout this project, and Kerry Emanuel for providing the single-column model and for his prompt response to our many questions. We also thank Richard Seager, Mike Wallace, Chris Bretherton, Clara Deser, R. Saravanan, David Battisti, and Michela Biasutti for helpful conversations. JCHC is supported through the NOAA Postdoctoral Program in Climate and Global Change, administered by the University Corporation for Atmospheric Research; and by the Joint Institute for the Study of the Atmosphere and Ocean/Climate Impact Group (JISAO/CIG) 
under NOAA Cooperative Agreement NAI17RJ1232. AHS is supported through NSF Grant ATM-0096195, NASA grant NAG5-10607, and a Fellowship for Science and Engineering from the David and Lucile Packard Foundation.

\section{REFERENCES}

Arakawa, A., and W. H. Schubert, 1974: Interaction of a cumulus cloud ensemble with the large-scale environment. Part I. J. Atmos. Sci., 31, 674-701.

Bantzer, C. H., and J. M. Wallace, 1996: Intraseasonal variability in tropical mean temperature and precipitation and their relation to the tropical 40-50 day oscillation. J. Atmos. Sci., 53, 3032-3045.

Betts, A. K., and W. Ridgeway, 1989: Climatic equilibrium of the atmospheric convective boundary layer over a tropical ocean. $J$. Atmos. Sci., 46, 2621-2641.

Bony, S., and K. A. Emanuel, 2001: A parameterization of the cloudiness associated with cumulus convection: Evaluation using TOGA COARE data. J. Atmos. Sci., 58, 3158-3183.

Brown, R. G., and C. S. Bretherton, 1997: A test of the strict quasiequilibrium theory on long time and space scales. J. Atmos. Sci., 54, 624-638.

Charney, J. G., 1963: A note on large-scale motions in the tropics. J. Atmos. Sci., 20, 607-609.

Chiang, J. C. H., Y. Kushnir, and S. E. Zebiak, 2000: Interdecadal changes in eastern Pacific ITCZ variability and its influence on the Atlantic ITCZ. Geophys. Res. Lett., 27, 3687-3690.

- - , and A. Giannini, 2002: Deconstructing Atlantic ITCZ variability: Influence of the local cross-equatorial SST gradient, and remote forcing from the eastern equatorial Pacific. J. Geophys. Res., 107, (D1), 148-227.

Chou, M.-D., D. P. Krantz, and W. Ridgeway, 1991: Infrared heating parameterizations in numerical climate models. J. Climate, 4 , 424-437.

Christy, J. R., and R. T. McNider, 1994: Satellite greenhouse signal. Nature, 367, 325.

Clement, A., and R. Seager, 1999: Climate and the tropical oceans. J. Climate, 12, 3383-3401.

Curtis, S., and S. Hastenrath, 1995: Forcing of anomalous sea-surface temperature evolution in the tropical Atlantic during Pacific warm events. J. Geophys. Res., 100, 15 835-15 847.

Da Silva, A. M., C. C. Young, and S. Levitus, 1994: Algorithms and Procedures. Vol. 1, Atlas of Surface Marine Data 1994, U. S. Department of Commerce, National Oceanic and Atmospheric Administration, $83 \mathrm{pp}$.

Elliot, J. R., S. P. Jewson, and R. T. Sutton, 2001: The impact of the 1997/98 El Niño event of the Atlantic Ocean. J. Climate, 14, 1069-1077.

Emanuel, K. A., 1991: A scheme for representing cumulus convection in large-scale models. J. Atmos. Sci., 48, 2313-2335.

- J. D. Neelin, and C. S. Bretherton, 1994: On large-scale circulation in convecting atmospheres. Quart. J. Roy. Meteor. Soc., 120, 1111-1143.

Fang, M., and K. K. Tung, 1996: A simple model of nonlinear Hadley circulation with an ITCZ: Analytic and numerical solutions. $J$. Atmos. Sci., 53, 1241-1261.

Giannini, A., J. C. H. Chiang, M. A. Cane, Y. Kushnir, and R. Seager, 2001: The ENSO teleconnection to the tropical Atlantic Ocean: Contributions of the remote and local SSTs to rainfall variability in the tropical Americas. J. Climate, 14, 4530-4544.

Gill, A. E., 1980: Some simple solutions for the heat-induced tropical circulation. Quart. J. Roy. Meteor. Soc., 106, 447-462.

Goddard, L., and N. E. Graham, 1999: Importance of the Indian Ocean for simulating rainfall anomalies over eastern and southern Africa. J. Geophys. Res., 104 (D16), 19 099-19 116.

Held, I. M., and A. Y. Hou, 1980: Nonlinear axially symmetric circulations in a nearly inviscid atmosphere. J. Atmos. Sci., 37, $515-533$.
Horel, J. D., and J. M. Wallace, 1981: Planetary-scale atmospheric phenomena associated with the Southern Oscillation. Mon. Wea. Rev., 109, 813-829.

Kalnay, E., and Coauthors, 1996: The NCEP/NCAR 40-Year Reanalysis Project. Bull. Amer. Meteor. Soc., 77, 437-471.

Kent, E. C., P. G. Challenor, and P. K. Taylor, 1999: A statistical determination of the random observational errors present in voluntary observing ships' meteorological reports. J. Atmos. Oceanic Technol., 16, 905-914.

Klein, S. A., and D. L. Hartmann, 1993: The seasonal cycle of low stratiform clouds. J. Climate, 6, 1587-1606.

— B. J. Soden, and N.-C. Lau, 1999: Remote sea surface temperature variations during ENSO: Evidence for a tropical atmospheric bridge. J. Climate, 12, 917-932.

Kumar, K. K., B. Rajagopalan, and M. A. Cane, 1999: On the weakening relationship between the Indian monsoon and ENSO. Science, 284, 2156-2159.

Lau, N.-C., and M. J. Nath, 1996: The role of the atmospheric bridge in linking tropical Pacific ENSO events to extratropical SST anomalies. J. Climate, 9, 2036-2057.

— and - 2001: Impact of ENSO on SST variability in the North Pacific and North Atlantic: Seasonal dependence and role of extratropical sea-air coupling. J. Climate, 14, 2846-2866.

Lindzen, R. S., and S. Nigam, 1987: On the role of sea-surface temperature gradients in forcing low-level winds and convergence in the tropics. J. Atmos. Sci., 44, 2418-2436.

Miller, R. L., 1997: Tropical thermostats and low cloud cover. J. Climate, 10, 409-440.

Neelin, J. D., and I. M. Held, 1987: Modeling tropical convergence based on the moist static energy budget. Mon. Wea. Rev., 115, $3-12$

— — low-frequency variability in the tropical atmosphere. J. Atmos. Sci., 44, 2341-2348.

Newell, R. E., and Z.-X. Wu, 1992: The interrelationships between temperature changes in the free atmosphere and sea surface temperature changes. J. Geophys. Res., 97 (D4), 3693-3709.

Norris, J. R., and C. B. Leovy, 1994: Interannual variability in stratiform cloudiness and sea surface temperature. J. Climate, 7, 1915-1925.

Pan, Y. H., and A. H. Oort, 1983: Global climate variations connected with sea surface temperature anomalies in the eastern equatorial Pacific Ocean for the 1958-73 period. Mon. Wea. Rev., 111, 1244-1258.

Philander, S. G. H., D. Gu, G. Lambert, N.-C. Lau, T. Li, and R. C. Pacanowski, 1996: Why the ITCZ is mostly north of the equator. J. Climate, 9, 2958-2972.

Pierrehumbert, R. T., 1995: Thermostats, radiator fins, and the local runaway greenhouse. J. Atmos. Sci., 52, 1784-1806.

Ramanathan, V., R. D. Cess, E. F. Harrison, P. Minnis, B. R. Barkstrom, E. Ahmad, and D. Hartmann, 1989: Cloud-radiative forcing and climate: Results from the Earth Radiation Budget Experiment. Science, 243, 57-63.

Raymond, D. J., and X. Zeng, 2000: Instability and large-scale circulations in a two-column model of the tropical troposphere. Quart. J. Roy. Meteor. Soc., 126, 3117-3135.

Rennó, N. O., K. A. Emanuel, and P. H. Stone, 1994: Radiativeconvective model with an explicit hydrologic cycle. 1: Formulation and sensitivity to model parameters. J. Geophys. Res., 99, 14 429-14 441.

Rossow, W. B., and R. A. Schiffer, 1991: International satellite cloud climatology project (ISCCP) cloud data products. Bull. Amer Meteor. Soc., 72, 2-20.

Saravanan, R., and P. Chang, 2000: Interaction between tropical Atlantic variability and El Niño-Southern Oscillation. J. Climate, 13, 2177-2194.

Satoh, M., 1994: Hadley circulation in radiative-convective equilibrium in an axially symmetric atmosphere. J. Atmos. Sci., 51, 1947-1968.

Schneider, E. K., 1977: Axially symmetric steady-state models of the 
basic state for instability and climate studies. Part II: Nonlinear calculations. J. Atmos. Sci., 34, 280-296.

Sobel, A. H., and C. S. Bretherton, 2000: Modeling tropical precipitation in a single column. J. Climate, 13, 4378-4392.

_, J. Nilsson, and L. M. Polvani, 2001: The weak temperature gradient and balanced tropical moisture waves. J. Atmos. Sci., 58, 3650-3665.

— I. M. Held, and C. S. Bretherton, 2002: The ENSO signal in tropical tropospheric temperature. J. Climate, 15, 2702-2706.

Soden, B. J., 2000: The sensitivity of the tropical hydrological cycle to ENSO. J. Climate, 13, 538-549.

Spencer, R. W., and J. R. Christy, 1992: Precision and radiosonde validation of satellite gridpoint temperature anomalies. Part I: MSU channel 2. J. Climate, 5, 847-857.

Wallace, J. M., 1992: Effect of deep convection on the regulation of tropical sea-surface temperatures. Nature, 357, 230-231.
Wu, Z., E. S. Sarachik, and D. S. Battisti, 2001: Thermally driven tropical circulations under Rayleigh friction and Newtonian cooling: Analytic solutions. J. Atmos. Sci., 58, 724-741.

Xie, P., and P. A. Arkin, 1997: Global Precipitation: A 17-year monthly analysis based on gauge observations, satellite estimates, and numerical model outputs. Bull. Amer. Meteor. Soc., 78, 25392558.

Yu, L., and M. M. Rienecker, 1999: Mechanisms for the Indian Ocean warming during the 1997-98 El Niño. Geophys. Res. Lett., 26, 735-738.

Yulaeva, E., and J. M. Wallace, 1994: The signature of ENSO in global temperature and precipitation fields derived from the microwave sounding unit. J. Climate, 7, 1719-1736.

Zebiak, S. E., 1993: Air-sea interaction in the equatorial Atlantic region. J. Climate, 6, 1567-1568.

, and M. A. Cane, 1987: A model El Niño-Southern Oscillation. Mon. Wea. Rev., 115, 2262-2278. 